\title{
Historical Basis of the Bodo Identity Formation
}

\author{
Dr. Oinam Ranjit Singh, PH.D. Guide ${ }^{1}$, Kumud Ranjan Basumatary ${ }^{2}$ \\ ${ }^{I}$ Associate Professor, Department of History Bodoland University, Kokrajhar, Assam, India. \\ ${ }^{2}$ Research Scholar, Department of History Bodoland University, Kokrajhar, Assam, India.
}

\begin{abstract}
The earliest settlers of the present state of Assam were the Bodos. They moulded powerful kingdoms in different names at different places in ancient and medieval periods. The Asura and Danava dynasties found mentioned in the Epics and Puranas, Salasthambas, Palas, Burmanas in ancient period and Chutiyas, Koches, Kacharies and Tiprahs in medieval period were all belonged to the great Bodo race. But all these powerful kingdoms are now represented by remnants of Koch kings of Bijni, Mongaldoi, Raja of Rani and Beltola. Since the ascendency of the Aryan race into Assam, all these kings by the influence of Brahmins became Hinduised caste of Kshatriyas except their subjects who did not follow their suit. But in recent times, the Neo-Vaishnavite religion was able to influence the common Bodo people to become saranias after they were being proselytized into this new faith. Again there was another wave of conversion from amongst the Bodos. This time, into Christianity after the coming of the British into Assam in 1826. Thus, hemmed in from all sides some sections from among the Bodos became alarmed at this sorry flight of the Bodos so much so that the extinction of the Bodos with their own culture and language was only the matter of time. At this critical moment, a neo-economic middle class from amongst the Bodos emerged. The new middle class became alert and to rescue the tribe from imminent peril, endeavoured to arouse consciousness by launching Socio-religious reformation movements under the leadership of Gurudev Kalicharan Brahma. Thus, from this period onwards, the Bodo identity formation took a massive form.
\end{abstract}

Keywords: Awakening, Feeling of Ethnicity, Pride and past glories, Barkandazes, Meches, Koches, Kacharis Ignorant, Illiteracy, Medieval Practices.

\section{INTRODUCTION}

In this dynamic world everything changes with time. So, to cope with the changing nature of the world, change for every society is necessary. The growth of ethnic consciousness at certain point of time is the sign of changing to cope with the changing world orders and this type of changes are in the field of social, economic, political and religion. The bringing about a change in any society is always accentuated by some vital factors- internal and external. The most vital point is the internal self realization and it is emanated from historical factors or past glories achieved by ancestors and aspirations for revival of the ancient glories leads to re-directing the societal activities which may be termed as awakening, consciousness, movements, sometimes revolution etc. The external factors that influences for arousing ethnic consciousness or awakening are the other civilization or achievement made by other neighbouring societies or inspirations drawn from changes brought about by other revolutions around the world. An external factor may also be the indirect, in disguise form of contributions of various agencies working for one's own interest but later becomes mutually beneficial. The western modern education introduced by the colonial rulers brought all sections of Indian society especially the down troddens to schools. Educated in modern fashion, the new elite class not only revived but also gave their own language in written and printed form and gained prominence in their respective regions. It is alleged that the colonial intention of introducing English education in India was for creating cadres for only clerical jobs requiring helping them in administration- home and abroad. But also it acted as blessings in disguise for the people classed as Vaishyas, Sudras and Nishadas who were not allowed to go to school to receive education alongside the sons of Brahmins and Kashatriyas in Sanskrit tols under a Brahmin Pandit. Not to speak of education for wild tribes of North-East India, they remained totally untouched and isolated and were quite ignorant what is going on in other parts of the world, nor was there any civilizing agent so as to bring them unto the light of education. During medieval India, education system was not universal but monopoly of a few sections of people. In that sense other sections of society remained largely deprived, oppressed, exploited, down-troddens and on the whole remained as servile groups. The tribes especially of north-east India were brought under education by the efforts of Christian Missionaries though intention was to convert them to Christianity. But it was a great blessings for the tribes where there was no effort made to bring them under education. The feeling for Indians by the Indians was not the order of the day nor was there any civilizing efforts made from within. Hence there is nothing wrong when this void was filled up by other people from outside who were somehow better off in so far as the feeling for humanity is concerned. 
For the Bodos the civilizing efforts and awakening or awareness or consciousness or feeling of ethnicity sprang up from within by the efforts of some sections of their population who gained awareness by virtue of little education they received and economic advantages they gained by involving themselves in Sal timber (Shorea Robusta) trade specially of Parbotjoar area of present districts of Dhubri and Kokrajhar (S.Barman, 1994:152). They tried to reorganize their social system in modern fashion by removing some of the medieval practices. They were responded enthusiastically by their people and the response was spontaneous for removing some evil social practices. The new elite class perceived that the excessive consumption of Zau (RiceBeer) and rearing of pigs in an unhygienic conditions, taking bride price, unsolicited marriage practices etc which actually became the source of mental anxiety for the educated Bodo elites were needed reformations. Earlier those who perceived shamefulness of these practices deliberately hid their antecedents and ethnic identity for fear of being hated by other neighbouring advance communities (B.Narzary \& M.Mitra, 2004:2). The efforts to set up schools in Bodo inhabited areas for bringing their children to school were made along with the social reformation movement and the spread of Brahma Faith of Srimot Kalicharan Gurudev by the neo-elite class of the Bodos. As there was none to help them in granting schools at decision making level, they necessitated political representation (K. Brahma (Jr) (Bang)1364:26). Hence, this hastened the formation of associations like the Bodo Chatra Sanmilani, the Bodo Mahasanmilani and later the Tribal League (the incipient political organization). Through these organizations, activities like social reformation, spreading of Brahma Faith and efforts to educate the Bodos continued in ever expanding horizon. The reassertion of the ethnic identity by way of safeguarding their own language, culture, traditions and reassurances of safety and security against social hatred for their medieval practices were the clear sign of the ethnic awakening for their identity formation politics.

The external factors like the spread of Christianity among the Bodos especially in the present district of Udalguri and the conversion of the large chunk of the Bodo population into Sarania after giving up their own language, religion and culture in favour of the Assamese language and Ek-sharan Dharma of Sri Sri Sankardev are another cause of concern for the Bodo elites who felt that the extinction of the Bodos as an ethnic community with language, religion and culture was only the matter of time. Thus, hemmed in from all sides, the Bodo elites felt for their fellow tribe who were actually at the mercy of the cruel situation during $19^{\text {th }}$ and early part of $20^{\text {th }}$ centuries (KR.Basumatary,1999:11). This ethnicity feeling accentuated them for arousing ethnic consciousness or awakening among the Bodos on the basis of history delineating the glorious past and they prided on the historical achievements of their ancestors. The awareness of the past glories of the Bodos came from the pages of history, the Epics, the Puranas and the Tantras of the medieval period. Besides many historical ballads, legends are still extant amongst the Bodos in the form of Oral History and Oral Traditions.

\section{OBJECTIVE OF THE STUDY}

The chief objective of this research paper is to present a systematic, comprehensive and graphic account of how the historical discourse of the Bodos help them in the formation of the Bodo identity in the early $20^{\text {th }}$ century.

\section{METHODOLOGY}

The study is a historical one. The work has primarily been based on all the literary texts which included consulting number of written sources and also on the official accounts left by the colonial administrators. However, a social anthropological approach is also adopted for the study.

\section{RESULT AND DISCUSSION}

Till now, a research study on the role of historical knowledge in the formation of the Bodo identity has not been done by any scholar utilizing all the available sources. Some scholars indeed, have brought to light the processes of the identity formation but the vital role the historical facts, artefacts etcetera have played was not seriously done by anyone before in their respective works. However, still await thorough investigation and treatment within a wide canvas. The Bodos those who had gained awareness took the pioneering role in making efforts to rescue the tribes from missing in oblivion which they by introducing Socio-Religious Reformation Movement became successful in saving the identity of the Bodos. The headings and subheadings that follow are the discussions on findings.

\section{THE BODOS IN THE HISTORICAL PERIODS:}

Assam has multi-racial and linguistic groups with distinct cultures of their own which are quite different from each other. The Boro Kacharis or the Boros forms a very numerous section of these groups and are believed to be the earliest settlers of Assam. At one point of time, they built a powerful kingdoms with their capitals at different places in the entire North-East India. Starting from Pragjyotishpur, Tezpur, Sadiya, Dimapur and then at Maibong and Khaspur(Haritikar), Tripura, Koch Behar, Bijni, Mongoldoi, Rani, Dimarua and many more bear testimony to the fact that the Bodos wielded power in the entire North-East India, North Bengal and 
some parts of the present Bangladesh from the ancient periods till recent times. The builders of these kingdoms were all closely allied to the great Bodo Race. They spread over the Brahmaputra valley, North Bengal and constitute a very important group of Indo-Mongoloid people of east India. Those people who lived in scattered hamlets along the foothills of Himalayas in north East India and Brahmaputra valley called themselves Boros or Bodos although they are otherwise known as Kacharis in the Assam valley (S.Endle, 1997:4). A section of this tribe who had gradually become Hindus speaking Assamese and considering their status to be higher than that of Kacharis is known as the Koch. In Brahmaputra valley, the greatest concentration of this tribe is in the district of Kokrajhar, Udalguri, Darrang, Barpeta, Nalbari, Kamrup, Goalpara and Nowgaon. They also skirted the southern bank of Brahmaputra and occupied the Garo Hills where the Garos still show close affinity with them. In the borders of north Cachar hills and Dimapur, there are two distinct groups known as Dimasas and Meches who also called themselves as Bodos or Kacharis. In the range of hill south of the Surma valley there are the Tipperahs whose language is a branch of the ancient Bodos (S.Endle, 1997:5).

Considering the linguistic affinities of the Kacharis or the Boros with the Garos as well as the tribes known under different names as Dhimal, Chutiyas, Koches, Rabhas, Meches, Lalungs, Sonowal etc many ethnographers opine the possibility of existence of some ethnological relationship between these tribes.

The modern Meches or the Boros were regarded in ancient times as Danavas, Asuras, Kiratas and Mlecchas by the Hindu scriptures. In the History of Assam, the Meches were the most numerous and ethnologically the most important group of people as these people had moulded and shaped the History of Pragjyotishpura and Kamrupa. Many scholars argue that from the records in the Epics- the Ramayana and the Mahabharata it is known that in the north eastern frontier kingdom of India a Mleccha territory ruled by the Bodo kings, referred to as Danavas and Asuras by the Aryans of the Gangetic valley, was known as Pragjyotisha and later as Kamrupa. N.N. Vasu says, "in the History of Kamrupa we find evidence of the rise of the Mleccha or Asura dynasty even during the ascendancy of the Aryans" (N.N. Vasu, 1983:34).

According to traditions, the earliest king of the Mech or Boros was Mahiranga Danava. The next king was Ghatak Asura. He was defeated and slain by another Asura named Narak Asura. After Narak Asura was slain by Krishna, his son Bhagadatta was installed as a king of Pragjyotishpura as mentioned in the Mahabharata. The Mahabharata bluntly declares Bhagadatta as a Mlecchanan Adhipati i.e. the ruler of Mlecchas. H.C. Ray says, "if there is any historical facts in the description of the great Epic then it is reasonable to regard Bhagadatta as a prince of the non-Aryan Tibeto-Chinese races, referred to as cinas, Kiratas in ancient Indian literature". Thus we find that the mythological kings of Assam and parts of Bengal racially belonged to the Mech or Bodo people.

The political history of the Meches or the Boros became comparatively clearer from the 4rth Century to the $12^{\text {th }}$ century A.D. for during this period we get some authentic sources like SIYUKI, Harsha Charita, Nidhanpur and Doobi copper plate grants. According to the Doobi copper plate grant Pushya Barman was the first king of Pragjyotishpura. H.C. Ray says that Pushya Barman belonged to the Bhagadatta dynasty and his lines were closely related with those of Salasthambha line. Now, Salasthambha was a Mech by race who shifted the capital from Pragjyotishpur to Sonitpur and built a Shiva temple (PN.Gohain Baruah,1976:140). One of the kings of Bhagadatta line was Kumar Bhaskar Barman.

It was during the reign of Kumar Bhaskara Barman that the famous Chinese traveler Hiuen Tsiang visited Kamrupa in 638 A.D. From the writings of Hiuen Tsiang we get some ethnological information of the inhabitants of Kamrupa in the days when Bhaskara Barman was the king of Kamrupa. S.K. Chatterjee writes, "the Mongoloid character of the people of the Country is clearly noted by the Chinese writer; the man are of small stature and their complexion a dark yellow; their language differ a little from that of mid-India (S.K. Chatterjee, 1974:16). During the medieval and modern period of Indian history a clearer written History of the Boros and the Kochs can be found from the Muslim and colonial writings.

The once powerful kingdom of Kamrupa is now represented by the Kings of Koch-Behar, Bijni, Darrang(Mongoldoi) and Beltola. During the colonial period the colonial ethnographers like S.Endle divided the Kacharis into western, eastern and southern Kacharis (S.Endle, 1997:5). The earliest notices of the eastern Kacharis were those of the Chutiyas. They had established a powerful kingdom on the Bank of the River Subansiri in the present Sadiya region.Another branch of the Kacharis was ruling over a region west of Sadiya, east of Dikhaumukh under one Manik Kachari. He was originally a small chieftain over twelve Kachari familes who later on subdued the surrounding villages and became famous with the title 'Kachari Raja' (PN.GohainBaruah,1976:142). At the same time, the southern Kacharis under Susengpha were also ruling over the strips of land between Dikhau and Dhansiri River with their capital at Dimapur. In 1229 A.D. Sukhapa, the founder of the Ahom kingdom in Assam of the great Shan or Tai race who came to Assam in 1228 A.D. after crossing Patkai hills established friendship with Bodoucha, the king of Mataks and Thakumtha, the king of Borahis and with other Kachari tribes (K. T. Phukan \& R. Barbarua,2013:23). 
Many references and mentions can be found in the writings of the colonial ethnographers about the present Meches or the Boros of erstwhile Goalpara district, present north Bengal which was known as Eastern Duars. They were B.C. Allen, W.W.Hunter, Bikramajit Harsat and Francis Hamilton.

Bikramajit Hasrat made a comment about the Meches or Kacharis of Eastern Duars of Bengal and Assam. He says, "the Meches were a hard working tribe and paid to the subah, the revenue in kind- Rice, Cloths, betel-nuts, cotton, butter and ghee"( B.J. Hasrat,1980:91). W.W. Hunter also remarked about the poor plight of the Bodo polity. He says, "the Meches or Kacharis do not seem to have achieved any form of polity of their own; they have few traditions, no ancient songs, no monuments, no written character or no literature of any kind" (W.W. Hunter, 1982:119).

\section{THEORETICAL FRAMEWORK AND SOME CONCEPTUAL DEFINITION OF TERMS Ethnic group:}

Historically the term ethnos has a pejorative connotation. Aristotle used this term to denote natural inferiority of the slaves to the citizens. There is however no general agreement as to what actually the term ethnic group means (BK.Roy Burman,1999:23). The concept of ethnic group refers to a community -type group of people who share the same culture or to descendents of such people who may not share this culture but who identify themselves with this ancestral group.

Glazer and Moynihan (1976) describes ethnic group as a social group which consciously shares some aspects of a common culture and is primarily be descent. Basing on Barth (1969), Hichs and Leis (1969) and others, Pathy(1988:18) observes that ethnic group is used in anthropological literature to designate a population which is a part of a plural society and yet is largely biologically self-perpetuating, shares a common cultural tradition and language, has an ascribed membership which identifies itself as being alike by virtue of a real or fictitious common ancestry, and is identified by others as constituting a distinct category in a plural society (BK.Roy Burman,1999:26,27).

\section{Ethnicity:}

There is however hardly any consensus about what constitutes ethnicity. The term ethnicity was first used by David Riesman in 1953 as referred to the 1972 supplement of Oxford English Dictionary (BK.Roy. Burman, 1999:31). Ethnicity is an ascribed identity or assigned status, something inherited from one's ancestors. Ethnicity is a very deeply rooted primal bond to one's ancestral bloodline.

The determining factor of ethnicity is common ancestry. In other words, people belong to an ethnic group because members of that group all share common biological and cultural origins (P.Q. Yang, 2000:42). Philip Q. Yang quotes primordialists, Geertz 1973, Issacs 1975, van den Berghe 1981 as saying that it is the primordial bonds that give rise to and sustain ethnicity. Primordialist argue that ethnicity is something given, ascribed at birth, deriving from the kin-and - clan-structure of human society, and hence something more or less fixed and permanent (W.W.Isajiw,1992:2). Ethnicity on the primordial system of categorization is an ascribed identity a status which is given to an individual or which one inherits from one's ancestor and this ascribed identity are fundamental and fixed. The most of the scholars apprehend ethnic group and ethnicity in the sense of consciousness of collective identity and historically crystallized sentiment associated with the identity in the context of the state (BK.Roy Burman, 1999:32).

The concept of ethnic group is the most basic, from which the others are derivative. He (Isajiw) argues that the concept of ethnicity is derived from the concept of ethnic group which refers to ethnicity as the collective phenomenon. Ethnic identity refers to ethnicity as an individually experienced phenomenon. Thus ethnicity itself is an abstract concept which includes an implicit reference to both collective and individual aspects of the phenomenon. According to him, ethnicity has both subjective and objective dimensions. Objective aspects are those which can be observed as facts in the existence of institutions, including that of kinship and descent and in overt behavior patterns of individuals. The subjective dimension refers to attitudes, values and pre-conceptions whose meaning has to be interpreted in the context of the process of communication. The terms ethnicity and ethnic group are often used interchangeably. But in actuality there is a nuance dividing them. While ethnic group is a social group based on ancestry, culture or national origin. Ethnicity refers to affiliation or identification with an ethnic group.

\section{Ethnic Identity}

Isajiw identifies two aspects of ethnic identity - internal and external. External aspect refers to observable behavior both cultural and social such as (I) speaking an ethnic language, practicing ethnic traditions (II) participation in ethnic personal networks, such as family and friendships (III) participation in ethnic institutional organizations such as Churches, schools, enterprise, media (IV) participation in ethnic voluntary organizations such as clubs, societies, youth organizations (V) participation in functions sponsored by ethnic organizations such as picnics, concerts, public lectures, rallies, dances. Internal aspect is the psychological 
affiliation of a person in which ethnic group was socialized (W.W.Isajiw, 1992:8). In the discourse of Social Science, the Bodos can be categorized as an ethnic group within Indian State-Nation, the characteristic features of which can be attributed to religion, sect, tribe, region, language, descent, race and culture. All these attributes are often used to define ethnic group and ethnicity. The phenomenon of ethnicity is the expressive aspect of ethnic group identities (J.Kamduk, vol.21, Issue 5:24).

\section{Bodo identity formation:}

A long historical process of identity formation among the Bodos took a nascent birth in the colonial period and in the post-colonial period it became more assertive. In the first half of the twentieth century some momentous changes in the collective life of the Bodos has taken place (H. M.Deka,2014:6). The strategic location of the Bodo settlements in the district of erstwhile Goalpara, opened up avenue for Timber Trade. In the erstwhile Goalpara district the Bodo occupied the strip of land lying north of present Gauripur Town starting from Rupsi covered with deep forest of Sal trees, further widening towards north-east direction, covering the areas of Parbotjoar, Guma, Ripoo, Cheerung, Sidli and Bijni Duars and this along with the spread of modern education led to the emergence of a small number of Bodo elite class which felt the need to reform the Bodo society to save it from the onslaught of religious conversion as well as complete assimilation to the greater Assamese society after becoming saranias. The pioneering leader in this direction is Gurudev Kalicharan Brahma who is regarded as the father of Brahma Movement. He was tired less in his work for reforming and developing Bodo society by removing its medieval practices. In his endeavours to uplift the Bodo society he was able to convince and enlist the support and assistance of the Bodo elite organizations. In this direction, the organizations like Bodo Chatra Sanmilani, Kachary Yubak Sanmilani, Bodo Mahasanmilani etc contributed a lot. This movement can be said particularly for establishing a distinct linguistic and cultural identity of the Bodos as a separate community (B.Narzary \& M.Mitra,2004:2).

Meanwhile the British government policy to provide special privileges to the tribal people of Assam led to the formation of a united political organization of all the plains tribal of Assam- the formation of Tribal League in 1933 and PTCA in later period can be attributed to this. After creating a strong political platform, the Bodo vis-à-vis the tribal leaders used this Tribal League to articulate their political aspirations and could play an important role in colonial Assam's legislative politics (H. M. Deka,2014:6).

After the Treaty of Yandaboo, the British made Assam an Indian province and brought it under one political formation. During British administration the entire north-east India, the home to various ethnic groups, directly or indirectly helped in developing identity consciousness -based on preservation of their own language and culture. The political power too considered necessary for acquisition of economic equality and opportunities for the respective communities (H. M. Deka,2014:6).

The pre-colonial society in Assam was semi-feudal and semi-tribal in which classical mode of production prevailed. The society was basically rural and the economy was self-sustaining in those days. Especially amongst the Bodos, the concept of surplus or commercial production was practically unknown. They cultivated a meager area of land which supplied them paddy just required for their families in a year. Before the introduction of modern administration by the British, the common Bodo people continued their age old practice of shifting cultivation. To meet their meager want they did not bother to engage themselves in trade and commerce except small volume of border trade with Bhutias in the north which they continued to maintain from ancient times upto $18^{\text {th }}$ century. The presence of Kachary-duars or passes or routes indicates that a considerable volume of barter trade between the Tawang hill tribes and the Bodos of Udalguri were carried on $(\mathrm{H}$. M. Deka,2014:21). Hence, taking cognizance of the main food items like Rice (paddy) pitha (steamed cake prepared from rice powder), Laru (sticky powdered rice fried in fats of pig), zau or rice-beer, the traditional Bodo beverage, the Bodos chiefly depended on rice product only. Hence, Bodos economy was rural agro-based economy. And thereby the Bodos were attached to the land. No land for the Bodos means no economic activity. Before the coming of the British into Assam vis-à-vis Goalpara district or before the introduction of modern administration by the British, sparsely populated Bodo villagers probably did not attract the attention of the zaminders to survey and make revenue assessment except in some settled cultivated land. Hence, they enjoyed land virtually free of taxes. This evasion though not intentional was made possible due to inaccessible forest villages coupled with absence of road-communication.

But with the coming of the British and subsequent introduction of modern administration, a complex economic situation had developed in the societies of Brahmaputra valley of Assam. The semi-feudal semi-tribal nature of economy and mode of production was replaced and linked with the capitalist world economy.

The Bodos in general suffered economically due to the British land revenue policies which made payment in cash mandatory. The British govt. got all the cultivated land surveyed and land revenue assessed which made the Bodo-life more complex ever due to absence of habitual cash transaction activity. The little volume of trade carried on by a few section of Bodo people with the Bhutias was bartered without cash. As the monetary system replaced the old bartered system the Bodo traders could not cope with the requirement of 
capital in their smallest transactions. The Bodo cultivators soon became more and more indebted to rich Barpetiah and Marwari money lenders due to their tricky money lending system and the land of the Bodos in subsequent periods passed into their hands and their land alienation started thereof (H. M. Deka,2014:21). More over the British administration tried to bring more and more land under cultivation for boosting land revenue collection since land revenue was the only and chief means of sources of the British administration. In their endeavour, sometimes the defaulters of land revenue were given more land for cultivation as they were not in a position to bear the brunt of pecuniary punishment and as the defaulters were given more land the cultivator become more defaulter and as a result the cultivators were compelled by situation to run away from his holdings who absconded in somewhere deep jungle to escape from the Barkandazes of the Zamindars as they were known for their notoriety towards defaulters of land revenue. In some cases, in order to avoid heavy burden of taxation, many poor Bodo peasants engaged themselves in wage-earning jobs in the tea plantations initiated by the British. In this case too freedom loving Bodos could not be effectively utilized by the British Tea planters. There were reports of frequent revolt and protest against them. They were soon substituted by other tribal communities from other regions of Indian subcontinent (H. M. Deka, 2014:21).

The land being an important factor for the stability of the Bodo economy, the question of giving protection to their land became by far the greatest economic issue for the Bodos. The introduction of new capitalist economy brought about by the new colonial administration hit hard the Bodo economy. Virtually there was no effort made to improve the cropping techniques and as a result the land productivity remained ever low which made the Bodo villagers indebted to rural money lenders and it was this indebtedness in turn had resulted in landlessness. The question of the loss of land is very serious for tribes because it practically means the loss of the only means of livelihood (H. M. Deka, 2014:22). The money economy, new system of taxes, commercialization of agriculture all of which were hitherto unknown to the Bodo villagers was the greatest blow to the Bodo economy with which they failed themselves to cope with. The Bodos were mainly agriculturalists whose only market economy is confined to a meager sale of vegetables, muster seeds and jute.

\section{CONCLUSION}

From Narak Asura of Pragjyotishpura to Gobinda Chandra of Dimapur since ancient times to the ascendancy of the British into Assam and annexation of the state of Cachar in 1854 by the British East India Company were the historical facts which bore testimony to the wielding of powers by the ancestors of the Bodos. These glorious historical antecedents were represented in the discourses of consciousness of their tribe by the elite class. They gazed back their national histories, traditions, language and culture which they got them in printed word in their periodical journal published from 1924 onwards called 'Bibar'. In much of their writings they compared their ancient glories achieved by their ancestors with that of their present deplorable conditions. Through various literary and cultural associations the growth of a conscious ethnic nationalism could be seen among the Bodos in the early part of the $20^{\text {th }}$ century. Some of the young minds of the Bodos took very active role in arousing national consciousness through their writings in the 'Bibar', the first and only journal so far brought out by the Bodos. In their writings the discourses of the past glories, rich cultural traditions, rich literatures etcetera were time and again and freely discussed deliberately in order to infuse enthusiasm of ethnicity feeling and ethnic identity as opposed to the idea of assimilation to the greater Assamese society. In the most of the colonizer's ethnographic, anthropological and administrative reports, the various tribes were demarcated from the mainstream Assamese by delineating that the tribes of Assam have their own separate rich culture, traditions, language and they were quite different from that of Hindu India which singly to a great extent encouraged many tribes to preserve their ethnic identities. Many linguistic and anthropological surveys were published in the early part of $20^{\text {th }}$ century which gave a direct impetus for clamouring separate status and identities for the tribes. With the occupation of Assam by the British in1826, the myth of higher caste privilege of monopoly of education faced steeped challenges from the establishments of educational institutions by the Missionaries in the second half of the $19^{\text {th }}$ century where many Bodo boys were admitted and were given free (from prejudice) and liberal education. The demarcation between various classes of people was inherent in the higher caste social system since ancient and medieval ages. The colonizer's writings only sparked the situations of volcanic eruptions.

\section{REFERENCES}

[1]. Barman, S. -Zamindari System in Assam During British Rule (A Case Study of Goalpara District), Spectrum publications, Guwahati,1994.

[2]. Narzary, B. \& Mitra, M.- Journey Towards Enlightenment : Gurudev And Bodo Soceity, GBD Publishers, Guwahati: Kolkata,2004.

[3]. Brahma K. (Jr) - Jieu Kourang Arw Saya, Bang.-1364, Kokrajhar.

[4]. Basumatary, K.R. -Oral Traditions and Reconstruction of the Past of the Bodos from 1752 to 1835,(M.Phil. dissertation, unpublished). 
[5]. Endle, S. - The Kacharies. Reprint, L.P.P. Delhi, 1997.

[6]. Anderson, J.D.-Introduction, a note on the Book The Kacharies by Rev. S Endle, Reprint,L.P.P. Delhi, 1997.

[7]. $\quad$ N.N. Vasu- Social History of Kamrupa. Northern Book Centre, New Delhi, 1983.

[8]. Baruah, PN.Gohain- Asomar Buranji, Asom Prakashan Parishad, Guwahati, 1976.

[9]. Chatterjee, S.K. - Kirata Jana Kriti, the Asiatic Society, Calcutta, 1974.

[10]. Phukan, K. T. \& R. Barbarua- Assam Buranji, Basu Publication, 2013.

[11]. Hasrat, B.J. - History of Bhutan, Education Deptt. R.Govt. of Bhutan, Thimphu, 1980.

[12]. Hunter, W.W. -Statistical Account of Assam. B.R.Publishing Corporation, Delhi, 1982.

[13]. Burman, BK.Roy.- Ethnicity, Nationalism and Integration: Conceptual Issues and the Indian Situation, inAjit K Danda(Ed) - Ethnicity,Nationalism and Integration,the Asiatic Soceity,Calcutta,1999.

[14]. Isajiw, W.W. -Definition and Dimensions of Ethnicity:A Theoretical Framework, University of Toronto,Paper presented at "Joint Canada-United States Conference on the Measurement of Ethnicity", Ottawa, Ontario, Canada, April 2,1992.Published in Challenges of Measuring an Ethnic World: Science,politics and reality.

[15]. Yang, P.Q. - Ethnic Studies: Issues and Approaches. State University of New York Press, 2000.

[16]. Kamduk,J.- Referred in Rise of Chakma Ethnic Consciousness in Arunachal Prodesh: An Intrumentalist Approach, IOSR Journal of Humanities and Social Science, vol.21, Issue 5.

[17]. Deka, H. M. - Politics of Identity and the Bodo Movement in Assam, Astral International, Pvt.Ltd. New Delhi, 2014. 